\title{
ANÁLISE ESPACIAL DA OCORRÊNCIA DO ÍNDICE DE CONE EM ÁREA SOB SEMEADURA DIRETA E SUA RELAÇÃO COM FATORES DO SOLO
}

\author{
JOSÉ P. MOLIN ${ }^{1}$, RAPHAEL P. DE MAGALHÃES ${ }^{2}$, GUSTAVO D. C. FAULIN ${ }^{2}$
}

\begin{abstract}
RESUMO: O presente estudo teve o objetivo de analisar, em uma lavoura sob semeadura direta, a distribuição vertical e horizontal da resistência à penetração medida por valores georreferenciados do índice de cone (IC) e a influência do teor de água do solo, permitindo a interpolação para análise de relações causa e efeito. Fatores importantes, como o teor de argila, silte, densidade, espaço poroso e teor de matéria orgânica do solo também foram mensurados. Utilizou-se de um penetrômetro hidráulico eletrônico, receptor de GPS, amostrador de solo e programas computacionais para o tratamento e obtenção dos resultados. A análise foi feita a partir dos mapas (não apresentados) para a espacialização dos atributos e pela regressão entre os dados interpolados por meio da função que apresentou o coeficiente de determinação $\left(\mathrm{R}^{2}\right)$ mais elevado. Constatou-se a ocorrência de valores maiores para o IC nas profundidades compreendidas de 0,10 a $0,15 \mathrm{~m}$, com menores valores em locais com maior teor de matéria orgânica, a qual coincidiu com maiores teores de argila e silte. O IC foi influenciado principalmente pelo teor de água, densidade e espaço poroso do solo.
\end{abstract}

PALAVRAS-CHAVE: compactação do solo, geoestatística, agricultura de precisão.

\section{SPATIAL ANALYSIS OF CONE INDEX UNDER NO-TILL AND ITS RELATIONSHIP WITH SOIL PHYSICAL ATTRIBUTES}

\begin{abstract}
The objective of this study was to measure the vertical and horizontal distribution of georeferenced values of cone index (CI) in a no-till field and the influence of soil water content. Data were interpolated to allow for cause and effect analysis. Other important factors as clay and silt content, bulk density, porous space and organic matter content were also measured. A penetrometer mounted on a tractor and equipped with a load cell was used together with GPS receiver, soil auger and computer programs to collect and analyze the data. Analysis was conducted based on maps of interpolated data after choosing the models with the highest determination coefficient $\left(\mathrm{R}^{2}\right)$ and regressions among them. High CI values were found at depths between 0.10 to $0.15 \mathrm{~m}$. Lower values of $\mathrm{CI}$ were associated with place of higher organic matter content, coincident with higher clay and silt content. CI was first influenced by the water content, bulk density and porous space.
\end{abstract}

KEYWORDS: soil compaction, geoestatistics, precision agriculture.

\section{INTRODUÇÃO}

A exploração dos solos para a produção de alimentos potencializa a sua degradação de diversas formas, sendo uma delas a compactação causada por máquinas e implementos agrícolas. GUPTA \& ALLMARAS (1987) descrevem a compactação como a compressão em estado nãosaturado do solo, caracterizada pelo decréscimo em volume e aumento da densidade, preferencialmente por meio da extrusão do ar dos seus poros. SEIXAS (1988) descreveu essa compactação por mudanças resultantes de aumento da densidade, decréscimo no volume de macroporos, infiltração e movimento interno de água mais lentos e maior resistência mecânica ao crescimento das raízes.

\footnotetext{
${ }^{1}$ Eng - Agrícola, Professor Livre-Docente, Departamento de Engenharia Rural, ESALQ/USP, Piracicaba - SP, Fone: (0XX19) 3429.4149,jpmolin@esalq.usp.br

${ }^{2}$ Eng $^{\mathrm{O}}$ Agrônomo, Mestre, Departamento de Engenharia Rural, ESALQ/USP, Piracicaba - SP.

Recebido pelo Conselho Editorial em: 15-7-2005
}

Aprovado pelo Conselho Editorial em: 19-4-2006 
Do ponto de vista agrícola, os sistemas de manejo que utilizam o preparo do solo para a produção vegetal resultam em perdas de matéria orgânica pela ruptura dos agregados e sua exposição (BRUCE et al., 1999). A diminuição da matéria orgânica causa o adensamento do solo, influenciando por isso no aumento da sua resistência à penetração. Contudo, o solo não será adensado quando, por outro lado, houver o incremento de matéria orgânica decorrente de maiores adições do que perdas por oxidação de carbono, o que ocorre em áreas sob semeadura direta (BRUCE et al., 1999; TRIPLETT JUNIOR \& VAN DOREN JUNIOR, 1969). Os teores de matéria orgânica nessas áreas podem alcançar ou até ultrapassar o dos ecossistemas naturais (SÉGUY \& BOUZINAC, 2001), sendo esse um dos motivos pelo qual a semeadura direta, apesar de sua interferência no aumento da densidade superficial dos solos, torna-se uma alternativa interessante.

Quando se utiliza o preparo periódico do solo, há o fracionamento de agregados. Na semeadura direta, com ausência de preparo e adição de matéria orgânica, os agregados se mantêm mais estáveis (CORRÊA, 2002), diminuindo a suscetibilidade do solo à compactação, a qual pode ser referenciada pelo índice de cone (IC) obtido por meio de penetrometria.

VASQUES et al. (1991) e TAYLOR (1963) comprovaram que a densidade e a umidade do solo são parâmetros importantes que influenciam no IC como caracterizador do seu estado de compactação. A variação da resistência à penetração dos solos pela modificação de seu teor de água também foi observada por KLEIN (1998). Já o teor de argila, segundo HAKANSSON et al. (1988) e LARSON et al. (1980), é uma das propriedades do solo que mais influencia na sua suscetibilidade de compactação, a qual diminui quando os agregados se encontram mais estáveis. Segundo BRADY \& WEIL (2002), a matéria orgânica confere estabilidade ao solo por favorecer a agregação por meio da junção de partículas minerais em estruturas granulares e pela sua participação na dinâmica da relação entre a estrutura mineral e os organismos do solo, como fungos, bactérias ou até raízes. Essa estabilização, de acordo com SIX et al. (2002), pode ocorrer basicamente pelos mecanismos de estabilização bioquímica e estabilização por associação com argila e silte, formando macroagregados (argilominerais) e proteção física no interior dos agregados.

A umidade do solo e os outros atributos têm variabilidade espacial e temporal, o que pode ocasionar variações na produção das lavouras. O recente avanço de novas técnicas, que no seu conjunto são denominadas de agricultura de precisão, fornece subsídios para o estudo dessas variabilidades por meio da interpolação dos dados, a qual pode ser executada utilizando-se da abordagem geoestatística, que consiste, segundo BRAGA (1990), na interpretação probabilística da teoria das variáveis regionalizadas. Essas mesmas técnicas de agricultura de precisão também permitem o tratamento localizado da ocorrência de compactação crítica.

Os resultados da análise geoestatística podem ser ilustrados por meio do mapa individual de parâmetros físicos e químicos do solo, facilitando a sua visualização. Estudos em condições norteamericanas indicam a relação da variabilidade espacial e temporal da produtividade das culturas a parâmetros físicos que, em última análise, se associam à drenagem dos solos, ultrapassando em importância os parâmetros da sua fertilidade (MOLIN, 2001).

Neste estudo, teve-se o objetivo de investigar a distribuição vertical e horizontal da compactação do solo por meio do resultado de mapas interpolados de seu IC, associado ao teor de água do solo. A densidade, o espaço poroso e os teores de argila, silte e matéria orgânica do solo também foram mensurados e incluídos na análise.

\section{MATERIAL E MÉTODOS}

O local de estudo constitui-se de área comercial localizada em uma fazenda no município de Tibaji - PR, com 21 ha e 10 anos sob semeadura direta, em uma região de clima denominado pela classificação de Köeppen como $\mathrm{Cfb}$, onde predomina a temperatura moderada com chuva bem distribuída e verão brando, com possibilidade de ocorrência de geadas, tanto no inverno como no 
outono. As médias de temperatura são inferiores a $20^{\circ} \mathrm{C}$, exceto no verão, e no inverno a média é inferior a $14{ }^{\circ} \mathrm{C}$, com mínimas inferiores a $8{ }^{\circ} \mathrm{C}$.

Foram realizadas amostragens georreferenciadas e planejadas em grade regular com o SIG SStoolbox (SST Development Group, Inc. ${ }^{\circledR}$ ) para a determinação da resistência à penetração do solo medida pelo IC, densidade, espaço poroso, teores de água, de argila, silte e matéria orgânica.

O IC foi mensurado utilizando-se do penetrômetro hidráulico eletrônico desenvolvido no Departamento de Engenharia Rural da ESALQ/USP e constituído de um cilindro hidráulico acoplado ao circuito hidráulico do trator, uma haste, que obedece às características estruturais e operacionais definidas pela norma ASAE S313.3, conectada a uma célula de carga de marca Gefran, modelo TG61-501 e capacidade de 4903 N, um sensor potenciométrico linear também de marca Gefran, modelo PCM-750 E de até $10 \mathrm{~K} \Omega$, ambos conectados a um computador portátil para a coleta dos dados. A velocidade de inserção da haste no solo foi calibrada em $0,03 \mathrm{~m} \mathrm{~s}^{-1}$.

A alocação dos pontos de amostragem no campo foi executada utilizando-se de um receptor de GPS com correção diferencial em tempo real por meio de duas antenas OmniStar ${ }^{\circledR}$. A navegação no campo foi feita com o programa Farm Site Mate (Farm Works Software ${ }^{\circledR}$ ), executado em computador de mão iPaq $\left(\mathrm{Compaq}^{\circledR}\right)$ conectado ao receptor.

As amostras de solo deformadas foram coletadas com um trado holandês e utilizadas na determinação de seu teor de água, argila, silte e matéria orgânica. As amostras indeformadas, utilizadas para a determinação da densidade e percentagem do espaço poroso, foram coletadas utilizando-se de anéis volumétricos, com volume médio de $55 \mathrm{~cm}^{3}$.

Para a análise do teor de água do solo, utilizou-se o método gravimétrico, que consiste na pesagem anterior e posterior à secagem em estufa a $105^{\circ} \mathrm{C}$ por $24 \mathrm{~h}$ (BLAKE \& HARTGE, 1986). Os dados do IC e a amostragem do solo relacionada à aquisição do seu teor de água foram coletados simultaneamente. $\mathrm{O}$ teor de argila do solo foi determinado pelo método do hidrômetro (EMBRAPA, 1997), e o de silte foi calculado por diferença. De forma semelhante à análise do teor de água, foi feita a determinação da densidade do solo (BLAKE \& HARTGE, 1986), diferenciado pelo fato de essa última ser coletada por anéis com volume conhecido. Para o cálculo do espaço poroso do solo, a densidade das partículas foi quantificada pelo método do picnômetro de água, descrito por BLAKE (1965), e o cálculo baseou-se na relação existente entre densidade do solo e dessas partículas.

A grade amostral média para o IC foi de 6,7 mensurações por hectare, com distância entre amostras de $35,5 \mathrm{~m}$. A grade relacionada ao teor de água, densidade e espaço poroso do solo utilizou quatro amostras por hectare, com distância entre amostras de $50,5 \mathrm{~m}$ e, para o teor de argila, silte e matéria orgânica do solo, utilizaram-se duas amostras por hectare, com distância entre amostras de 71,0 m. A determinação do teor de água do solo foi efetuada com amostras coletadas nas profundidades de 0,00 a 0,20 e de 0,20 a $0,40 \mathrm{~m}$. A densidade e o espaço poroso do solo foram obtidos em amostras extraídas na profundidade de 0,15 a $0,20 \mathrm{~m}$, e o teor de argila, silte e matéria orgânica, com amostras compostas por sete subamostras, obtidas na profundidade de 0,00 a $0,20 \mathrm{~m}$. Para promover a coincidência da profundidade dos valores de IC com os demais atributos do solo estudados, foi calculada a média desse índice para o intervalo requerido, obtendo-se valores de IC médio nas profundidades de 0,00 a 0,20; 0,15 a 0,20 e de 0,20 a 0,40 m.

Para a análise estatística descritiva dos dados coletados, foi utilizado o programa Statistica (StatSoft Inc. ${ }^{\circledR}$ ), sendo as análises geoestatísticas executadas utilizando-se do programa Vésper 1.5 (MINASNY \& MCBRATNEY, 2002). Transformaram-se os dados brutos que não apresentaram normalidade com o objetivo de obter a distribuição normal, verificada pelo método descrito por SHAPIRO \& WILK (1965), utilizando-se, para tanto, da retirada daqueles dados candidatos a discrepantes e a transformação do conjunto de dados pelas transformadas matemáticas, como o logaritmo na base 10, a raiz quadrada e o seno hiperbólico do inverso da raiz quadrada. A partir dos dados tratados, com os quais foi possível obter distribuição normal, foi feita a análise geoestatística, e para os atributos em que também foi constatada a continuidade espacial, foram 
obtidos os semivariogramas ajustados e seus parâmetros - efeito pepita, alcance, patamar e função utilizados para a realização da interpolação por meio da krigagem. Para os demais atributos que não apresentaram distribuição normal ou continuidade espacial, por apresentarem efeito pepita puro (valores de semivariância iguais para o efeito pepita e patamar), ou para aqueles que apresentaram modelo sem patamar (alcance e patamar não puderam ser aferidos com a amostragem efetuada), utilizou-se, para a geração dos mapas, o método de interpolação do inverso da distância. Os valores interpolados foram utilizados nas análises de regressão entre os fatores, nas quais foi ajustado o modelo que apresentou maior coeficiente de determinação $\left(\mathrm{R}^{2}\right)$. Utilizou-se do programa Excel (Microsoft ${ }^{\circledR}$ ) para a execução das regressões e ajuste dos modelos.

As regressões efetuadas relacionam-se ao IC com os teores de água, argila e silte; ao teor de água com os teores de argila e silte; ao IC com o teor de matéria orgânica, densidade e espaço poroso do solo; teor de matéria orgânica com os teores de água, argila e silte do solo, e entre a densidade e espaço poroso com os teores de água, argila, silte e matéria orgânica do solo.

\section{RESULTADOS E DISCUSSÃO}

Por meio da mensuração do IC constatou-se a ocorrência de compactação superficial do solo sob semeadura direta na área de estudo, acentuando-se na profundidade de 0,10 a $0,15 \mathrm{~m}$, como observado anteriormente por MOLIN \& SILVA JÚNIOR (2003). Os parâmetros estatísticos de todos os resultados obtidos encontram-se na Tabela 1. Os conjuntos de dados que não apresentaram distribuição normal, ou seja, tiveram o valor W inferior a 0,95 (SHAPIRO \& WILK, 1965), passaram a apresentar tal distribuição após a retirada dos candidatos a discrepantes e diversas transformações dos dados. A exceção ocorreu com os dados referentes ao teor de água na profundidade de 0,20 a $0,40 \mathrm{~m}$, teor de matéria orgânica e de argila.

Com essas transformações, foi possível realizar a análise geoestatística, adquirindo os parâmetros do semivariograma ajustado aos dados que apresentaram distribuição normal. Esses resultados são apresentados na Tabela 2 . Os dados de IC nas profundidades de 0,20 a 0,25 m, teor de água de 0,00 a 0,20 m e densidade do solo de 0,15 a 0,20 m apresentaram dependência espacial forte, e os demais apresentaram dependência espacial moderada, segundo CAMBARDELA et al. (1994), os quais indicam dependência forte para o valor do efeito pepita em relação ao valor máximo da semivariância menor do que $25 \%$, moderada se essa relação for entre 25 a $75 \%$ e fraca se a mesma for maior do que $75 \%$.

O valor do alcance dos atributos, em geral, foi maior do que a distância entre as amostras, indicando que as amostragens foram suficientes para detectar a dependência espacial existente. $\mathrm{O}$ alcance do IC nas profundidades de 0,00 a 0,05 e 0,30 a $0,35 \mathrm{~m}$ e do teor de silte na profundidade de 0,00 a $0,20 \mathrm{~m}$ não puderam ser determinados com a quantidade de amostras coletadas em campo. Seus modelos não atingiram o patamar, fornecendo, por esse motivo, dados insuficientes para a interpolação por krigagem, embora tenha sido detectada dependência espacial. Esses parâmetros foram interpolados pelo método do inverso da distância. $\mathrm{O}$ mesmo interpolador também foi utilizado para os dados que não apresentaram distribuição normal: teor de água de 0,20 a 0,40 $\mathrm{m}$, teor de argila e de matéria orgânica na mesma profundidade.

As regressões com os dados interpolados são apresentadas na Figura 1. No caso do teor de água relacionado com o IC (Figuras 3.1 e 3.2), o modelo ajustado aos dados para as faixas de profundidades de 0,00 a $0,20 \mathrm{~m}$ e 0,00 a $0,40 \mathrm{~m}$ demonstra existir relação inversa, ou seja, quando o teor de água aumenta, o IC decresce, tendendo à estabilização. Entre esses atributos, o melhor ajuste do modelo ocorreu na camada mais superficial $(0,00$ a $0,20 \mathrm{~m})$, uma vez que, nessa profundidade, o modelo foi suficiente para explicar $62 \%$ da variabilidade dos dados, enquanto na profundidade de 0,20 a $0,40 \mathrm{~m}$ o modelo foi suficiente para explicar apenas $24 \%$ da variabilidade.

A capacidade de a matéria orgânica e a argila armazenarem água (BRADY \& WEIL, 2001) pode ter proporcionado os bons ajustes entre esses atributos, uma vez que o modelo entre o teor de matéria orgânica e o teor de água (Figura 1.10) foi suficiente para explicar $77 \%$ da variabilidade 
dos dados e $85 \%$ entre o teor de argila e o teor de água (Figura 1.8). O comportamento desses modelos, em ambos os casos, evidencia relação diretamente proporcional com o aumento dos teores de argila e matéria orgânica, resultando em maiores teores de água no solo, em uma função que tende à estabilização, no primeiro caso, e em comportamento linear, no segundo.

TABELA 1. Parâmetros da estatística descritiva referentes ao IC, teor de água, teor de matéria orgânica, teor de argila, densidade e espaço poroso do solo.

\begin{tabular}{|c|c|c|c|c|c|c|c|}
\hline $\begin{array}{l}\text { Profundidade } \\
(\mathrm{m})\end{array}$ & Média & Mínimo & Máximo & Variância & $\begin{array}{l}\text { Desvio- } \\
\text { Padrão }\end{array}$ & $\begin{array}{l}\text { Coeficiente } \\
\text { de Variação }\end{array}$ & $\mathrm{W}^{*}$ \\
\hline & \multicolumn{7}{|c|}{$\mathrm{IC}(\mathrm{MPa})$} \\
\hline 0,00 a 0,05 & 1,13 & 0,39 & 2,29 & 0,15 & 0,39 & 34,51 & $0,98 * *$ \\
\hline 0,05 a 0,10 & 2,12 & 0,42 & 4,47 & 0,47 & 0,68 & 32,08 & $0,98 * *$ \\
\hline 0,10 a 0,15 & 2,28 & 0,51 & 4,68 & 0,65 & 0,81 & 35,53 & $0,97 * *$ \\
\hline 0,15 a 0,20 & 2,21 & 0,74 & 6,09 & 0,73 & 0,85 & 38,46 & 0,93 \\
\hline 0,20 a 0,25 & 2,17 & 0,82 & 6,22 & 0,58 & 0,76 & 35,02 & 0,92 \\
\hline 0,25 a 0,30 & 2,13 & 0,71 & 6,95 & 0,50 & 0,71 & 33,33 & 0,83 \\
\hline 0,30 a 0,35 & 2,06 & 0,38 & 7,70 & 0,52 & 0,72 & 34,95 & 0,71 \\
\hline 0,35 a 0,40 & 2,09 & 0,75 & 7,31 & 0,67 & 0,82 & 39,23 & 0,64 \\
\hline 0,00 a 0,20 & 1,93 & 0,57 & 3,71 & 0,33 & 0,57 & 29,53 & $0,97 * *$ \\
\hline \multirow[t]{2}{*}{0,20 a 0,40} & 2,11 & 1,17 & 6,45 & 0,40 & 0,63 & 29,86 & 0,78 \\
\hline & \multicolumn{7}{|c|}{ Teor de água $(\%)$} \\
\hline 0,00 a 0,20 & 15,87 & 9,21 & 27,94 & 22,69 & 4,76 & 29,99 & 0,92 \\
\hline \multirow[t]{2}{*}{0,20 a 0,40} & 16,40 & 10,48 & 27,70 & 20,70 & 4,55 & 27,74 & 0,90 \\
\hline & \multicolumn{7}{|c|}{ Teor de argila $(\%)$} \\
\hline \multirow[t]{2}{*}{$\underline{0,00}$ a 0,20} & 21,50 & 11,50 & 42,30 & 83,39 & 9,13 & 42,47 & 0,86 \\
\hline & \multicolumn{7}{|c|}{ Teor de silte $(\%)$} \\
\hline \multirow[t]{2}{*}{0,00 a 0,20} & 7,52 & 3,50 & 16,40 & 112,14 & 3,45 & 45,88 & 0,91 \\
\hline & \multicolumn{7}{|c|}{ Espaço poroso $(\%)$} \\
\hline \multirow[t]{2}{*}{0,15 a 0,20} & 44,98 & 28,44 & 59,56 & 56,74 & 7,53 & 16,74 & $0,98 * *$ \\
\hline & \multicolumn{7}{|c|}{ Teor de matéria orgânica $\left(\mathrm{g} \mathrm{dm}^{-3}\right)$} \\
\hline \multirow[t]{2}{*}{0,00 a 0,20} & 23,86 & 14,00 & 40,00 & 59,20 & 7,69 & 32,23 & 0,91 \\
\hline & \multicolumn{7}{|c|}{ Densidade do solo $\left(\mathrm{g} \mathrm{cm}^{-3}\right)$} \\
\hline 0,15 a 0,20 & 1,34 & 0,98 & 1,70 & $2,9010^{-2}$ & 0,17 & 12,69 & $0,98 * *$ \\
\hline
\end{tabular}

Por outro lado, solos com maior teor de argila e matéria orgânica tendem a apresentar valores maiores para a capacidade de campo (BRADY \& WEIL, 2001), o que aumenta a quantidade de água necessária para alcançar o teor citado por HENDERSON et al. (1988), de 70\% da capacidade de campo, no qual a diminuição da água aumenta exponencialmente a sua influência na resistência do solo à penetração. Tal situação é indicativa de que não se pode tecer considerações conclusivas a respeito da menor influência no IC, na região com maior teor de água, a qual também apresenta maior teor de argila e de matéria orgânica.

Em relação ao IC, os teores de matéria orgânica e de argila (Figuras 3.3 e 3.5) resultaram em relações inversamente proporcionais, sendo essas coerentes no primeiro e incoerentes, à primeira vista, no segundo caso. A correlação negativa entre IC e o teor de argila pode ser explicada considerando que as posições com maior teor de argila apresentaram maiores teores de água e matéria orgânica, fatores que tendem a diminuir a resistência do solo à penetração (IC). 
TABELA 2. Parâmetros relativos ao ajuste do semivariograma para o IC, teor de água, densidade e espaço poroso do solo.

\begin{tabular}{|c|c|c|c|c|c|}
\hline $\begin{array}{l}\text { Profundidade } \\
\text { (m) }\end{array}$ & Efeito pepita $(\mathrm{C} 0)$ & $\begin{array}{l}\text { Patamar } \\
(\mathrm{C} 0+\mathrm{C} 1)\end{array}$ & Alcance (m) & Função & $\begin{array}{c}(\mathrm{C} 0100) /(\mathrm{C} 0+\mathrm{C} 1) \\
(\%)\end{array}$ \\
\hline & \multicolumn{5}{|c|}{ IC } \\
\hline 0,00 a $0,05^{*}$ & -- & -- & -- & -- & -- \\
\hline 0,05 a 0,10 & 0,19 & 0,35 & 505,8 & Exponencial & 54,3 \\
\hline 0,10 a 0,15 & 0,30 & 0,54 & 213,6 & Exponencial & 55,5 \\
\hline 0,15 a 0,20 & 0,20 & 0,39 & 42,8 & Exponencial & 51,3 \\
\hline 0,20 a 0,25 & 0,08 & 0,35 & 41,3 & Exponencial & 22,9 \\
\hline 0,25 a 0,30 & 0,08 & 0,25 & 48,0 & Exponencial & 32,0 \\
\hline 0,30 a $0,35^{*}$ & -- & -- & -- & -- & -- \\
\hline 0,35 a 0,40 & $1,110^{-2}$ & $1,710^{-2}$ & 73,4 & Exponencial & 64,7 \\
\hline 0,00 a 0,20 & 0,16 & 0,25 & 81,5 & Exponencial & 64,0 \\
\hline \multirow[t]{2}{*}{0,20 a 0,40} & $4,210^{-3}$ & $8,810^{-3}$ & 174,0 & Esférico & 47,7 \\
\hline & \multicolumn{5}{|c|}{ Teor de água } \\
\hline \multirow[t]{2}{*}{0,00 a 0,20} & $3,010^{-3}$ & $12,510^{-3}$ & 148,6 & Exponencial & 24,0 \\
\hline & \multicolumn{5}{|c|}{ Densidade do solo } \\
\hline \multirow[t]{2}{*}{0,15 a 0,20} & 0,00 & 0,03 & 129,3 & Esférico & 0,0 \\
\hline & \multicolumn{5}{|c|}{ Espaço Poroso } \\
\hline \multirow[t]{2}{*}{0,15 a 0,20} & 38,55 & 59,55 & 291,9 & Esférico & 64,7 \\
\hline & \multicolumn{5}{|c|}{ Teor de silte } \\
\hline 0,00 a $0,20 *$ & -- & -- & -- & -- & -- \\
\hline
\end{tabular}

*Modelo sem patamar

O modelo ajustado para a relação entre o teor de argila e o teor de matéria orgânica (Figura 1.19) foi suficiente para explicar $85 \%$ da variação dos dados e, em relação ao teor de silte e ao teor de matéria orgânica (Figura 1.20), o modelo explicou 82\% dessa variação. Os resultados evidenciam a existência de maior teor de matéria orgânica nos locais com maior teor de argila e silte. Esses valores apontam para a formação de macroagregados argilominerais, como sugerido por SIX et al. (2002). Como o teor de silte é mensurado por diferença, não cabem muitas considerações conclusivas a respeito de sua influência na formação de compostos argilominerais. Contudo, a semelhança das regressões dos teores de silte e argila é notável.

Os resultados indicam que a condição de maior teor de matéria orgânica foi eficaz na manutenção da estrutura física do solo nos locais com maior teor de argila e silte, diminuindo o potencial de compactação pela manutenção de sua agregação e percentagem de espaço poroso, situação também constatada por ETANA et al. (1997) e ASSOULINE et al. (1997). Esse fato pode ser visualizado pela correlação existente entre o teor de matéria orgânica com a densidade e percentagem do espaço poroso do solo, ambos indicadores do seu grau de compactação. No caso da densidade do solo, a sua relação com a matéria orgânica (Figura 1.17) demonstra comportamento inversamente proporcional, ou seja, quanto maior o teor de matéria orgânica, menor é a densidade do solo em uma função que explicou $47 \%$ da variabilidade dos dados e com tendência à estabilização da densidade do solo em baixos valores com o aumento da matéria orgânica. Quanto ao espaço poroso, sua relação com o teor de matéria orgânica (Figura 1.18) foi proporcional, com uma função suficiente para explicar 50\% da variabilidade dos dados. Entre a densidade do solo e a sua porosidade, há forte relação, uma vez que um valor é função do outro em uma relação linear inversamente proporcional, suficiente para explicar $96 \%$ da variabilidade dos dados (Figura 1.21). 

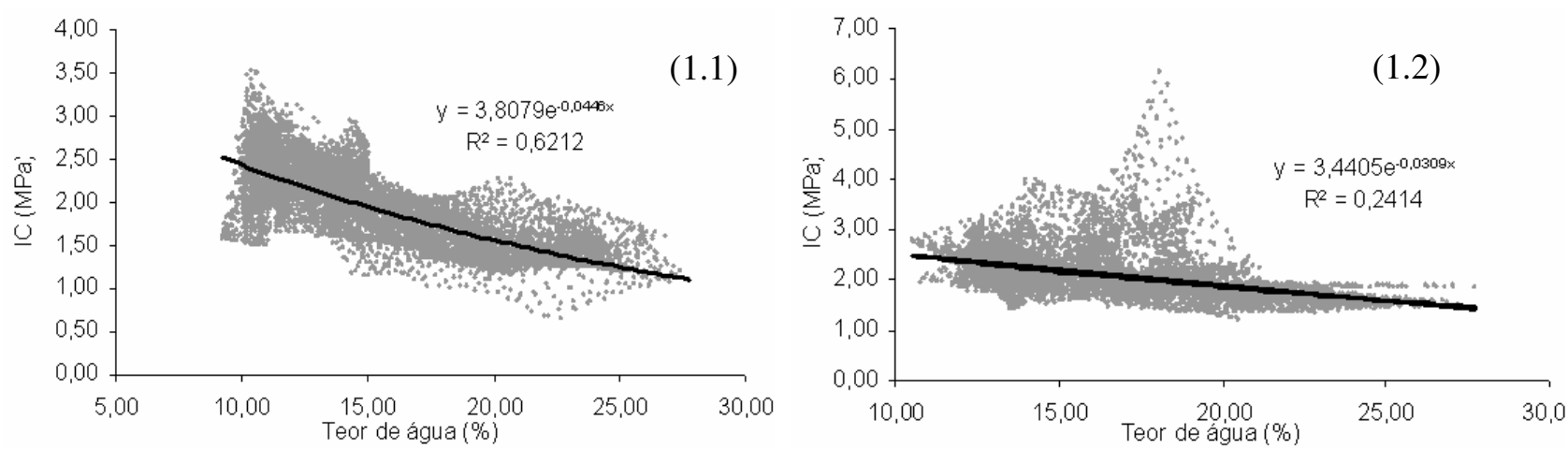

Teor de água e IC de 0,00 a $0,20 \mathrm{~m}$

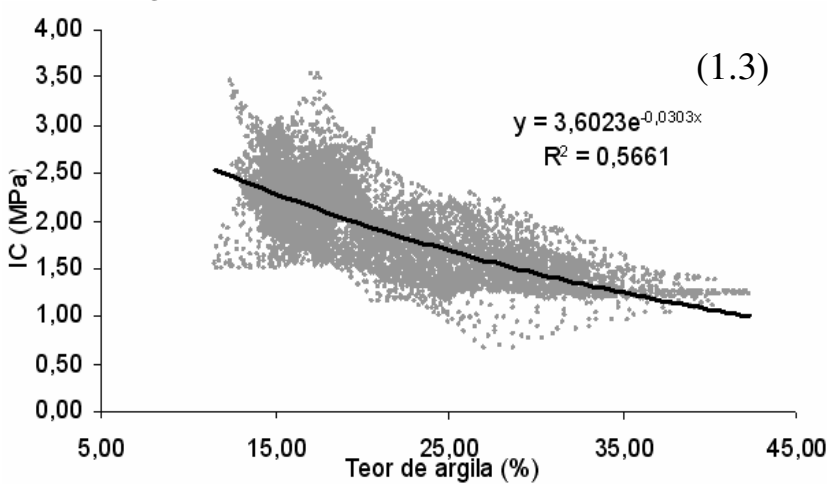

Teor de água e IC de 0,20 a $0,40 \mathrm{~m}$

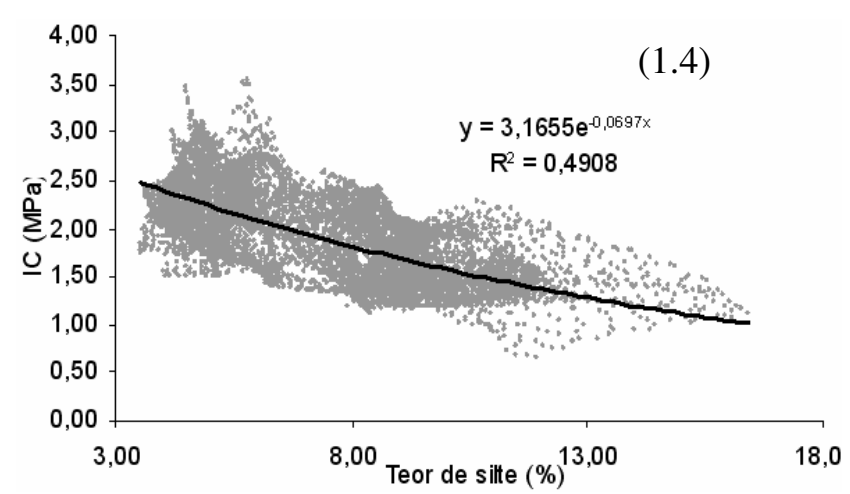

Teor de argila e IC de 0,00 a $0,20 \mathrm{~m}$

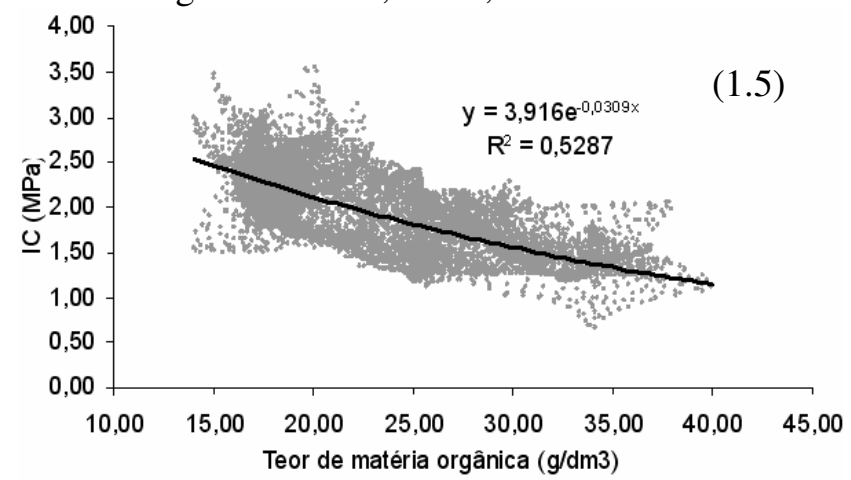

Teor de silte e IC de 0,00 a $0,20 \mathrm{~m}$

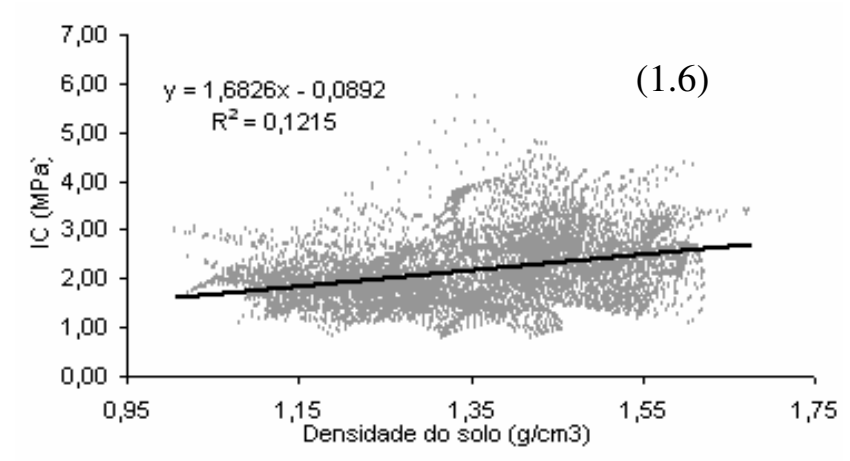

Teor de matéria orgânica e IC de 0,00 a 0,20 m

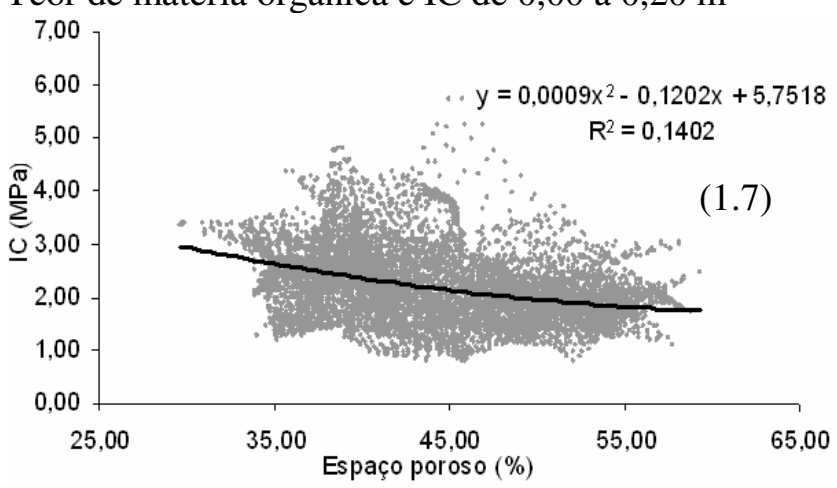

Densidade e IC de 0,15 a $0,20 \mathrm{~m}$

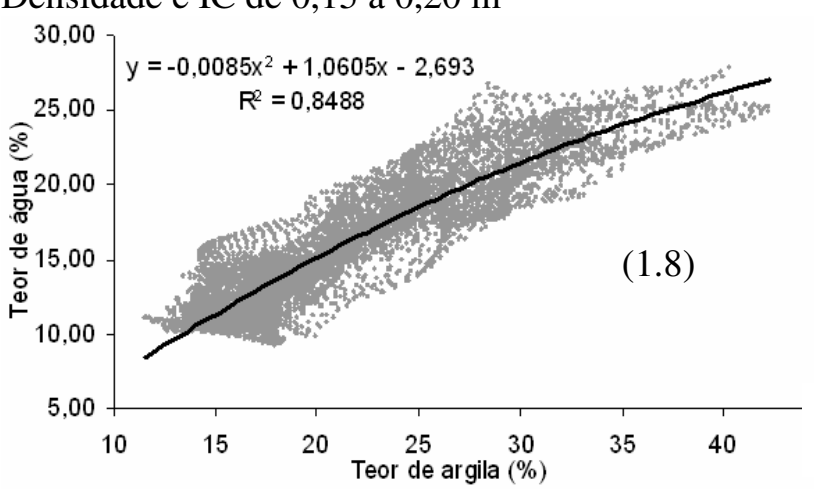

Teores de argila e de água de 0,00 a $0,20 \mathrm{~m}$

Espaço poroso e IC de 0,15 a $0,20 \mathrm{~m}$.

FIGURA 1. Regressões entre os dados interpolados dos atributos estudados. 

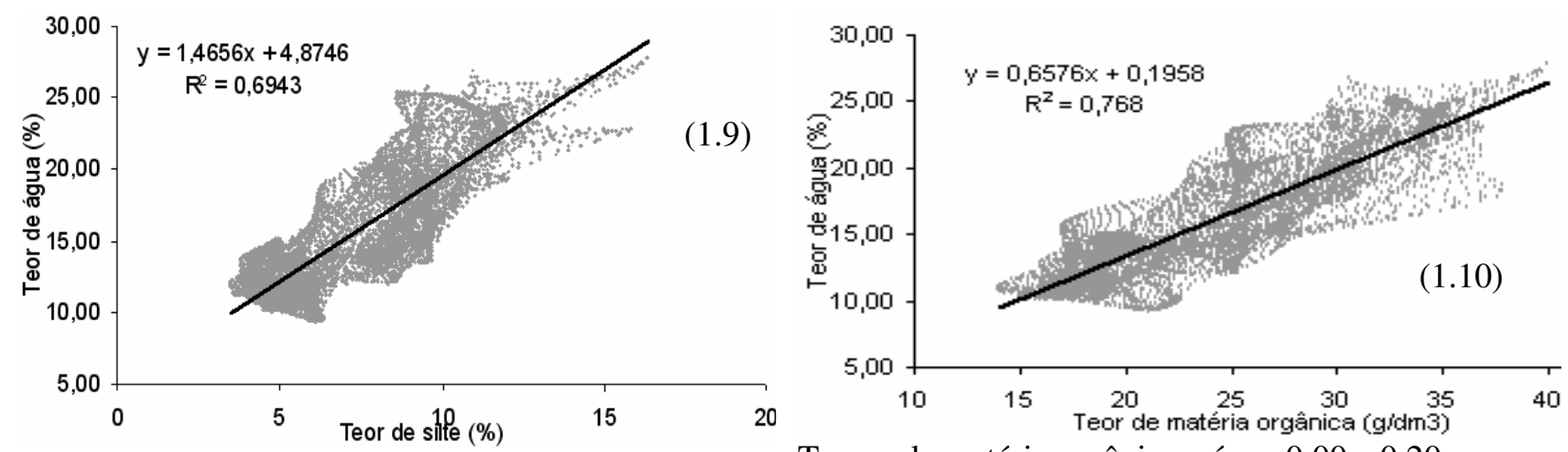

Teores de silte e de água de 0,00 a 0,20

Teores de matéria orgânica e água 0,00 a 0,20 m
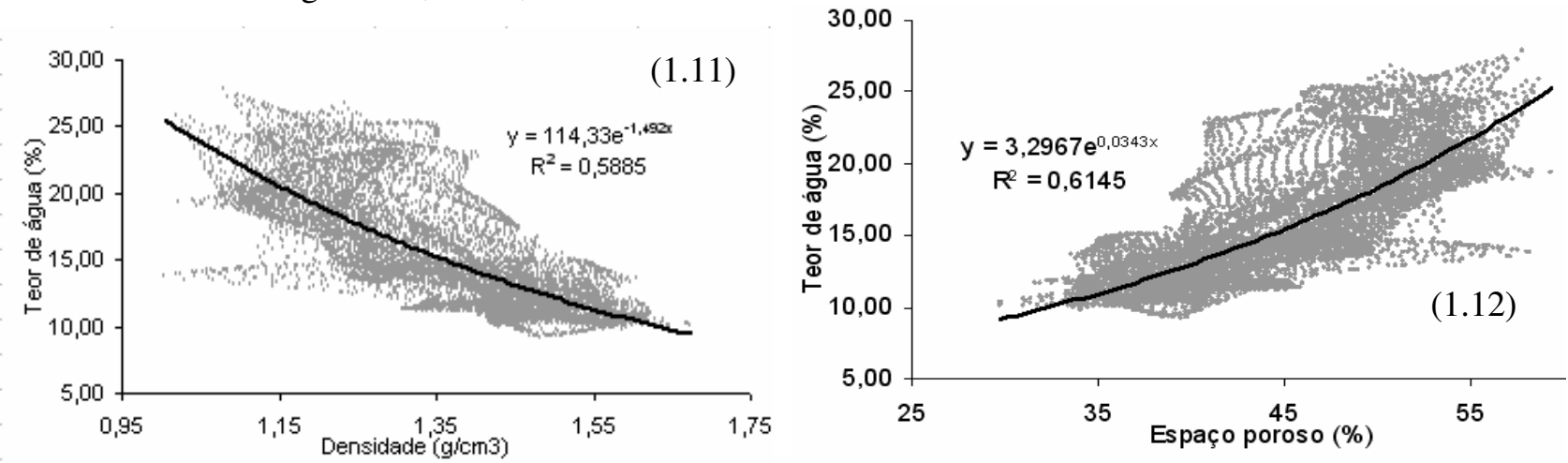

Densidade de 0,15 a $0,20 \mathrm{~m}$ e teor de água de 0,00 a $0,20 \mathrm{~m}$

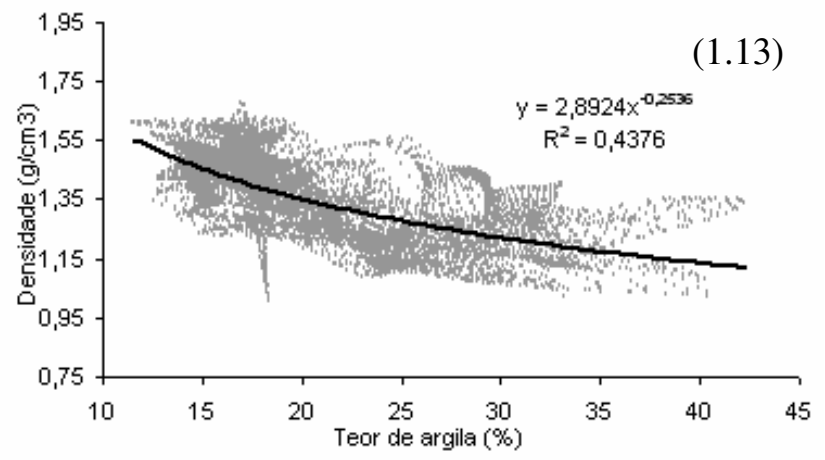

Espaço poroso de 0,15 a $0,20 \mathrm{~m}$ e teor de água de 0,00 a $0,20 \mathrm{~m}$

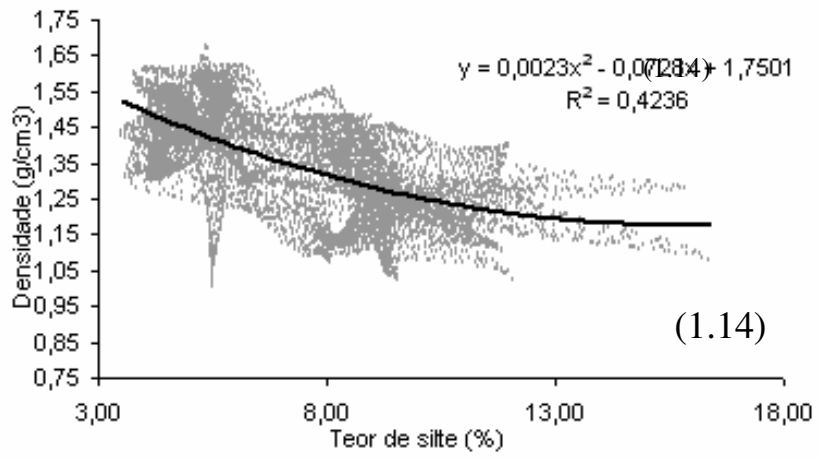

Teor de argila de 0,00 a 0,20 e densidade do solo de 0,15 a $0,20 \mathrm{~m}$

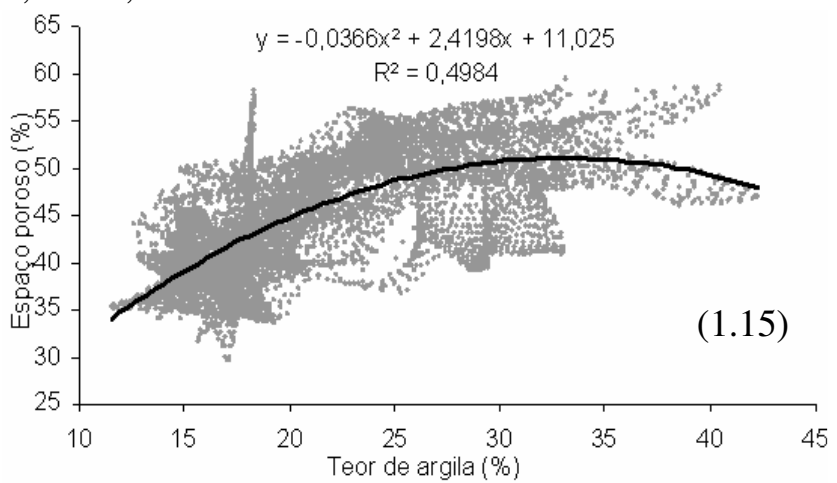

Teor de silte de 0,00 a 0,20 e densidade do solo de 0,15 a $0,20 \mathrm{~m}$

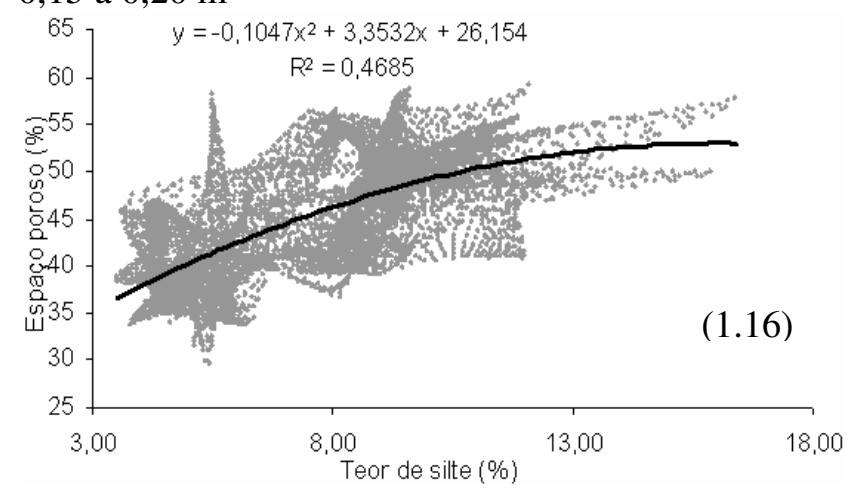

Teor de argila de 0,00 a $0,20 \mathrm{~m}$ e espaço poroso de Teor de silte 0,00 a $0,20 \mathrm{~m}$ e espaço poroso de 0,15 a 0,15 a $0,20 \mathrm{~m}$ $0,20 \mathrm{~m}$

FIGURA 1. Regressões entre os dados interpolados dos atributos estudados. 

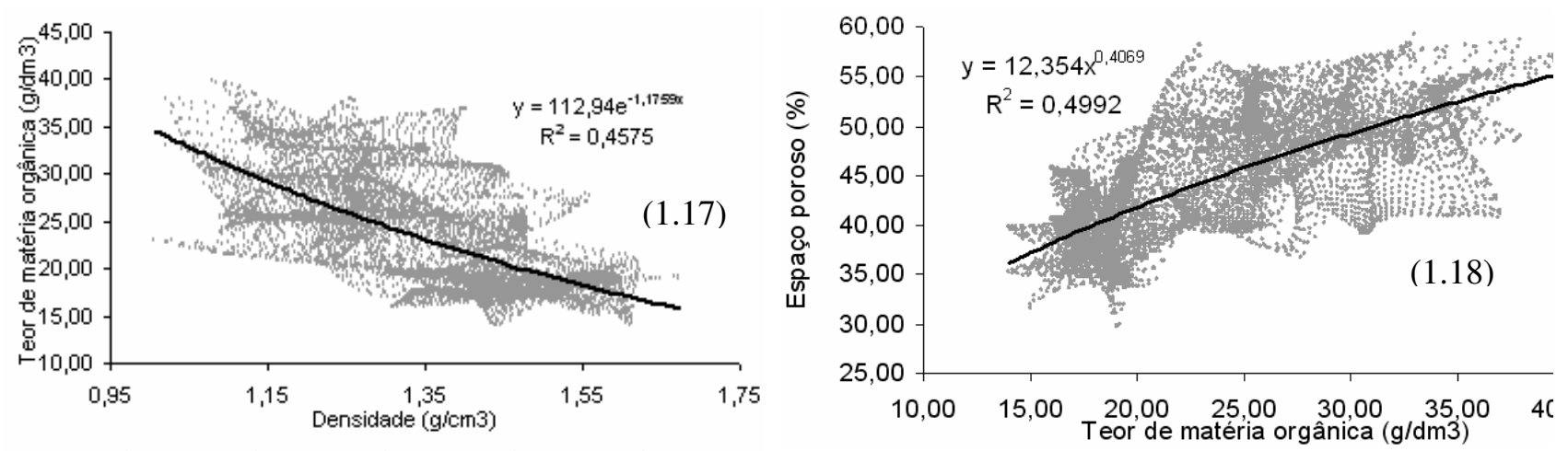

Teor de matéria orgânica de 0,00 a $0,20 \mathrm{~m}$ e densidade do solo de 0,15 a $0,20 \mathrm{~m}$

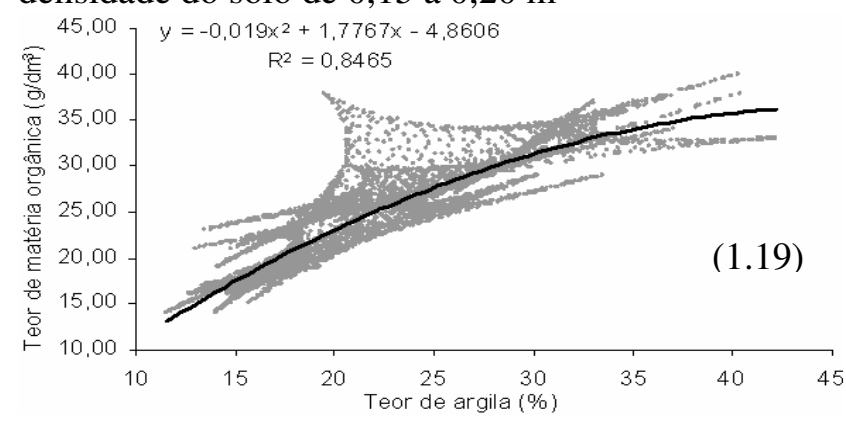

Teores argila e matéria orgânica de 0,00 a 0,20 m

Teor de matéria orgânica de 0,00 a 0,20 m e espaço poroso de 0,15 a $0,20 \mathrm{~m}$

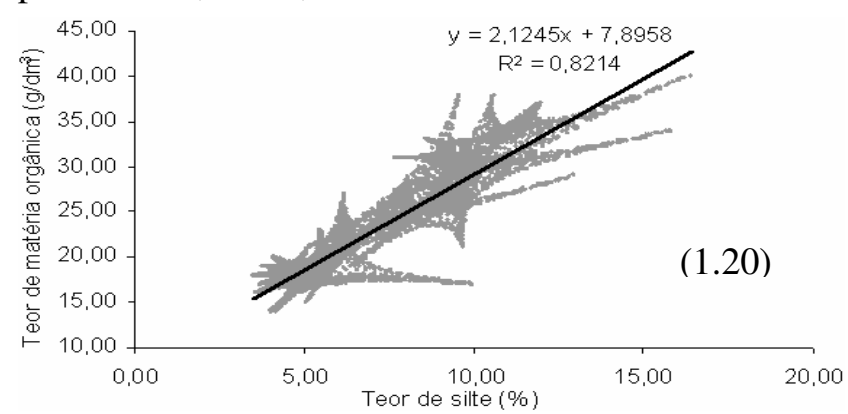

Teores silte e matéria orgânica de 0,00 a $0,20 \mathrm{~m}$

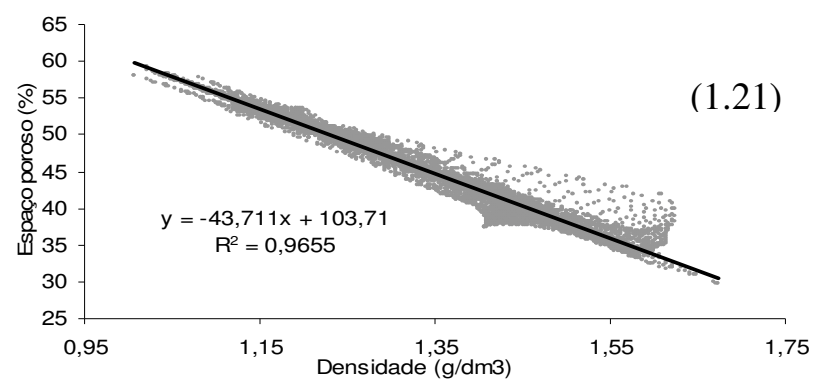

Espaço poroso e densidade de 0,15 a 0,20 m

FIGURA 1. Regressões entre os dados interpolados dos atributos estudados.

Constatou-se crescimento exponencial do teor de água com o aumento de poros e decréscimo, também de forma exponencial, quando relacionado à densidade do solo (Figuras 1.11 e 1.12). Os solos com maior percentagem de espaço poroso e menor densidade apresentam maior espaço para o armazenamento de água e são potencialmente melhor drenados (TEIXEIRA et al., 2000). Nesse caso, observou-se que, nas regiões com maior espaço poroso e menor densidade, o teor de água aumentou sensivelmente. Contudo, esse espaço poroso foi conservado, frente às pressões de compactação, nas regiões do talhão com solo mais argiloso, pelo maior teor de matéria orgânica presente, o que certamente influenciou no aumento da capacidade do solo dessas regiões em reter água.

A regressão entre a densidade e o espaço poroso do solo com o IC evidencia que o aumento da densidade causou crescimento linear no IC. Porém, com ajuste da função suficiente para explicar apenas $12 \%$ da variabilidade dos dados (Figura 1.6), e entre o IC e o espaço poroso, essa relação foi inversa, com uma função tendendo à estabilização e suficiente para explicar 14\% dessa variabilidade (Figura 1.7). Esses resultados demonstram que os valores de IC foram eficazes para indicar a presença de compactação do solo, uma vez que a compactação, como descrita por SEIXAS (1988) e GUPTA \& ALLMARAS (1987), é a ocorrência do aumento da densidade e decréscimo no volume de poros. 
A forma de análise, com a interpolação de valores a partir de dados georreferenciados, permitiu a integração de todos os fatores, como observados em condições e em escala real de campo. Além da importância incontestável da influência do teor de água, densidade e espaço poroso do solo nas variações do IC, constatou-se que os teores de argila, silte e matéria orgânica apresentaram considerável interação com esse índice.

\section{CONCLUSÕES}

Por meio da mensuração do IC em grade amostral na área estudada, constatou-se a ocorrência de valores mais elevados nas profundidades de 0,10 a 0,15 m. Esses valores foram maiores nas regiões com menor teor de argila e matéria orgânica. $O$ teor de argila deve ser considerado em estudos sobre a resistência do solo à penetração, uma vez que atua disciplinando o teor de água, o qual pode diminuir a resistência do solo à penetração medida com penetrômetro.

A análise entre indicadores diretos e indiretos, tais como IC, umidade, densidade, espaço poroso, teores de argila, silte, matéria orgânica e outros, é possível por meio da utilização de dados georreferenciados e interpolados desses atributos. No entanto, há necessidade de estudos adicionais em relação à influência espacial do teor de argila e silte no que se refere à formação de compostos argilominerais e à diminuição do potencial de compactação dos solos com maiores teores dessas frações minerais em sistemas sob semeadura direta.

\section{AGRADECIMENTOS}

Ao CNPq, pelo apoio financeiro à execução do projeto e aos proprietários da fazenda por fornecerem as condições locais.

\section{REFERÊNCIAS}

ASSOULINE, S.; TAVARES, J.; TESSIER, D. Effect of compaction on soil physical and hydraulic properties: experimental results and modeling. Soil Science Society of America Journal, Madison, v.61, n.2, p.390-8, 1997.

BLAKE, G.R. Bulk density. In: BLAKE, C.A. (Ed.) Methods of soil analysis: physical and mineralogical properties, including statistics of measurement and sampling. Madison: American Society of Agronomy, 1965. p.374-90.

BLAKE, G.R.; HARTGE. K.H. Bulk density. In: KLUTE, A. (Ed.) Methods of soil analysis. Part 1: Physical and mineralogical methods. $2^{\text {nd }}$ ed. Madison: SSSA, 1986. p.363-75.

BRADY, C.B.; WEIL, R.R. The nature and properties of soils. $3^{\text {th }}$ ed. New York: Prentice Hall, $2001.960 \mathrm{p}$.

BRAGA, L.P.V. Geoestatística e aplicações. Rio de Janeiro: Departamento de Métodos Estatísticos do Instituto de Matemática da Universidade Federal do Rio de Janeiro, Rio de Janeiro, 1990. $36 \mathrm{p}$.

BRUCE, J.P.; FROME, M.; HAITES, E.; JANZEN, H.; LAL, R. Carbon sequestration in soils. Journal of Soil and Water Conservation, Ankeny, v.54, n.1, p.382-9, 1999.

CAMBARDELLA, C.A.; MOORMAN, T.B.; NOVAK, J.M.; PARKIN, T.B.; KARLEN, D.L.; TURCO, R.F.; KONOPKA, A.E. Field-scale variability of soil properties in central lowa soils. Soil Science Society of America Journal, Madison, v.58, n.5. p.1501-11, 1994.

CORRÊA, J.C. Efeito de sistemas de cultivo na estabilidade de agregados de um Latossolo Vermelho-Amarelo em Querência - MT. Pesquisa Agropecuária Brasileira, Brasília, v.37, n.2, p.203-9, fev. 2002.

EMPRESA BRASILEIRA DE PESQUISA AGROPECUÁRIA. Manual de métodos de análise de solo. 2.ed. Rio de Janeiro, 1997. 212 p. 
ETANA, A.; COMIA, R.A.; HADANSSON, I. Effects of uniaxial stress on the physical properties of four Swedish soils. Soil and Tillage Research, Amsterdam, v.44, n.1, p.13-21, 1997.

GUPTA, S.C.; ALLMARAS, R.R. Models to access the susceptibility of soil to excessive compaction. Soil Science, New York, v.6, n.1, p.65-100, 1987.

HAKANSSON, I.; VOORHEES, W.B.; RILEY, H. Vehicle and wheel factors influencing soil compaction and crop response in different traffic regimes. Soil and Tillage Research, Amsterdam, v.11, n.3-4, p.239-82, 1988.

HENDERSON, C.; LEVETT, A.; LISLE, D. The effects of soil water content and bulk density on the compactibility of some western Australina sandy soils. Australian Journal of Soil Research, Collingwood, v.26, p.391-400, 1988.

KLEIN, V.A. Propriedades físico-hídrico-mecânicas de um latossolo roxo, sob diferentes sistemas de uso e manejo. 1998. 150 f. Tese (Doutorado em Solos e Nutrição de Plantas) - Escola Superior de Agricultura "Luiz de Queiroz”, Universidade de São Paulo, Piracicaba, 1998.

LARSON, W.E.; GUPTA, S.C.; USECHE, R.A. Compression of agricultural soil from eight soil orders. Soil Science Society of America Journal, Madison, v.44, n.3, p.450-7, 1980.

MINASNY, B.; MCBRATNEY, A.B. Fuz ME version 2.1. Australian Center for Precision Agriculture. The University of Sydney, fev. 2002. Disponível em:

<http://www.usyd.edu.au/su/agri/acpa>. Acesso em: 20 nov. 2003.

MOLIN, J.P. Agricultura de precisão: o gerenciamento da variabilidade. Piracicaba: ESALQ, USP, $2001.83 \mathrm{p}$.

MOLIN, J.P.; SILVA JÚNIOR, R.L. Variabilidade espacial do índice de cone, correlacionada com textura e produtividade. Engenharia Rural, Piracicaba, v.14, n.único, p.49-57, 2003.

SEIXAS, F. Compactação do solo devido à mecanização florestal: causas, efeitos e práticas de controle. Piracicaba: IPEF, 1988. p.1-10 (Circular técnica, 163).

SÉGUY, L.; BOUZINAC, S. Direct seeding on plant covers: sustainable cultivation of our planet's soils. In: CONGRESS ON CONSERVATION AGRICULTURE: A WORLDWIDE

CHALLENGE, 1., 2001, Madri. Proceedings... Madri: FAO/ECAI, 2001. v.1, p.85-92.

SHAPIRO, S.S.; WILK, M.B. An analysis of variance test for normality. Biometrika, Oxford, v.52, p.591-611, dec. 1965.

SIX, J.; FELLER, C.; DENEF, K.; OGLE, S.M. Soil organic matter, biota and aggregation in temperate and tropical soils - Effects of no-tillage. Agronomie, Davis, v.22, p.755-75, mai. 2002.

TAYLOR, H.M.; GARDNER, H.R. Penetration of cotton seedling taprots as influenced by bulk density, moisture content, and strength of soil. Soil Science, New York, v.96, n.3, p.153-6, Sep. 1963.

TEIXEIRA, W.; TOLEDO, M.C.M.; FAIRCHILD, T.R.; TAIOLI, F. Decifrando a terra. São Paulo: Oficina de Textos, 2000. 558 p.

TRIPLETT JUNIOR, G.B.; VAN DOREN JUNIOR, D.M. Nitrogen, phosphorus and potassium fertilization of non-tilled maize. Agronomy Journal, Madison, n. 61, p.637-9, 1969.

VASQUES, L.; MYHRE, D.L.; HANLON, E.A.; GALLAHER. R.N. Soil penetrometer resistance and bulk density relationships after long term no tillage. Commun Soil Science Plant, Mendonça, Anal 22, p.2101-17, 1991. 